\title{
Energetics of lower tropospheric ultra-long waves: A key to intra-seasonal variability of Indian monsoon
}

\author{
S M BAWISKAR*, M D ChIPADE and P V PURANIK \\ Indian Institute of Tropical Meteorology, Dr. Homi Bhabha Road, Pune 411 008, India. \\ *e-mail: bawiskar@hotmail.com
}

\begin{abstract}
Analysis of fifty four (1951-2004) years of daily energetics of zonal waves derived from NCEP/ NCAR wind ( $u$ and $v$ ) data and daily rainfall received over the Indian landmass (real time data) during southwest monsoon season (1 June-30 September) indicate that energetics (momentum transport and kinetic energy) of lower tropospheric ultra-long waves (waves 1 and 2) of low latitudes hold a key to intra-seasonal variability of monsoon rainfall over India.

Correlation coefficient between climatology of daily (122 days) energetics of ultra-long waves and climatology of daily rainfall over Indian landmass is 0.9 . The relation is not only significant but also has a predictive potential. The normalised plot of both the series clearly indicates that the response period of rainfall to the energetics is of 5-10 days during the onset phase and 4-7 days during the withdrawal phase of monsoon over India. During the established phase of monsoon, both the series move hand-in-hand. Normalised plot of energetics of ultra-long waves and rainfall for individual year do not show marked deviation with respect to climatology. These results are first of its kind and are useful for the short range forecast of rainfall over India.
\end{abstract}

\section{Introduction}

Indian monsoon is not a local phenomenon. It interacts with other components of global circulations in a significant way. Fluctuations in the monsoon are the reflection of the fluctuations in the global circulations. Global circulations have wave-like character. The characteristics of a wave can be studied through its amplitude and phase. Fourier technique provides the easiest method to compute the amplitude and phase of the waves. This technique has been used by many research workers. Saltzman (1957) for the first time derived equations governing the energetics of the largescale of the atmospheric turbulence in the domain of wave number. Saltzman and Fleisher (1960) studied rate of transfer of kinetic energy between different scales of eddies and showed that the intermediate waves (wave numbers $5-10$ ) were source of kinetic energy to long waves (wave numbers 1-4) and short waves (wave numbers 11-16). Saltzman
(1970) summarized the results of several studies of energy interactions in the Fourier domain in extra-tropical regions where synoptic-scale baroclinic disturbances are dominant. Keshavamurty and Awade (1974) showed that smaller waves were very pronounced during May to July 1972. Asnani and Awade (1978) presented a model of abnormal monsoon in India and proposed that in the absence of accurate normal global upper air patterns, a study of global upper air pattern during contrasting summer monsoon activity is an acceptable way to get an idea of large-scale anomalies in the global flow pattern. Krishnamurti and Kanamitsu (1981) examined upper tropospheric large scale circulation features for two contrasting monsoon years and showed the contrasting behaviour of wave number 3. Murakami (1981) studied the energetics considering standing and transient scales and showed that standing waves are source of kinetic energy to transient waves. Raja Rao et al (1983) studied the stratospheric

Keywords. Energetics; ultra-long waves; momentum transport; kinetic energy; Indian summer monsoon rainfall. 
activities through transport of momentum and sensible heat for waves 1 and 2. Awade et al (1982) computed wave to wave and wave to zonal flow kinetic energy exchanges in wave number domain and showed that long waves (wave numbers 1-2) were the source of kinetic energy to other waves and zonal mean flow. Bawiskar et al (1989) computed transport of momentum for contrasting monsoon years and showed that small scale disturbances were intense during normal monsoon years. Intensification (weakening) of planetary waves enhances (suppresses) the rainfall activity over India (Bawiskar et al 2002). Significant release of kinetic energy by wave number 1 might have played a vital role in triggering five intense systems over the Bay of Bengal during 1997 whereas the weak supply of kinetic energy by wave 1 might have failed to trigger even a single system during monsoon 2002 (Bawiskar et al 2005a). Eight to ten days prior to active (break) phase of monsoon, there is northward (southward) penetration of kinetic energy of extra-tropical short waves (Bawiskar et al 2005b). These studies clearly indicate that all India summer monsoon rainfall is related to the energetics of the zonal waves on various spatial and temporal scales. In the present study, the relationship between energetics of ultra-long waves and rainfall received over the Indian landmass on a daily scale during northern summer monsoon season is discussed.

\section{Data and methodology}

Daily global NCEP/NCAR wind $(u$ and $v$ ) data at 850,500 and $200 \mathrm{hPa}$ for a period from 1 June to 30 September (122 days) of 54 years (19512004) are considered. Daily All India Monsoon Rainfall (DAIMR) are taken from daily gridded rainfall data published by India Meteorological Department (Rajeevan et al 2006) for the same period and years. Wind data are decomposed into spectrum of zonal waves and energetics (momentum transport and kinetic energy) of the waves are computed following Bawiskar et al (1995).

\section{Results}

We have considered first ten waves for the study because our earlier study (Bawiskar 2003) shows that the variance explained by first ten waves is $95 \%$ or more. The series of energetics of each of the waves at 850,500 and $200 \mathrm{hPa}$ levels for 122 days (1 June-30 September) are correlated with DAIMR. This analysis is carried out for the individual years from 1951 to 2004.

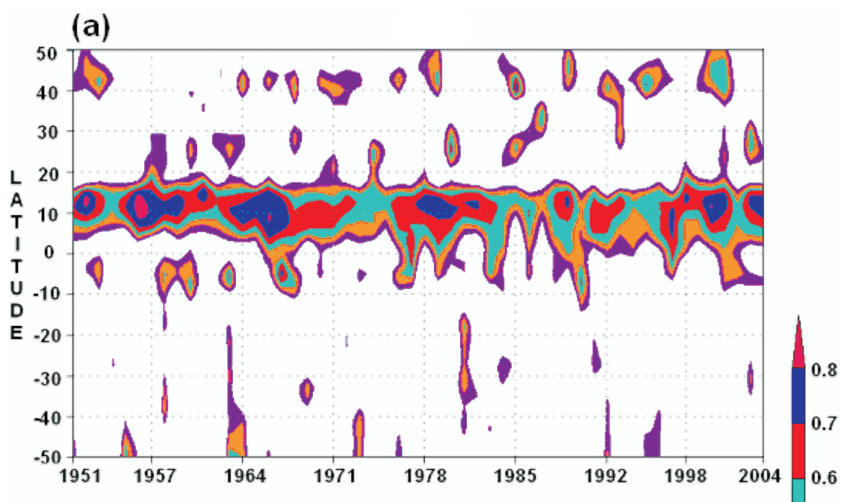

(b)

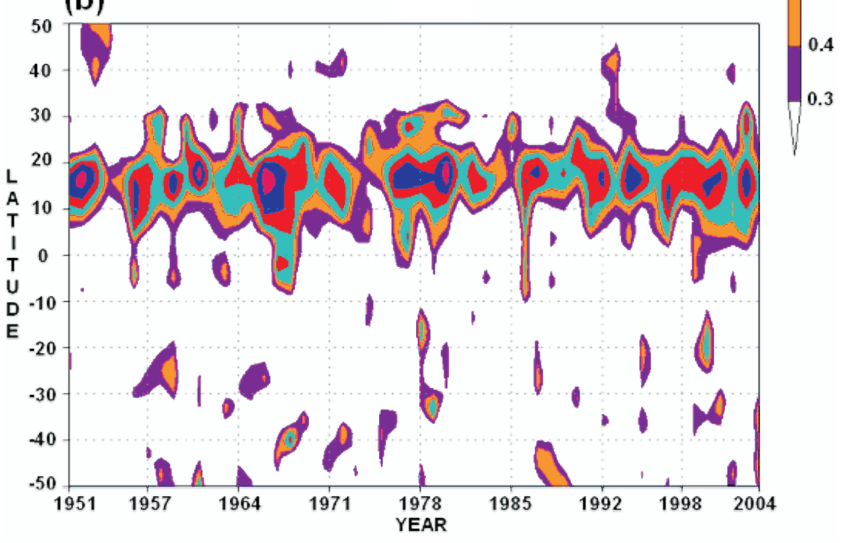

Figure 1. Latitudinal and inter-annual variation of correlation coefficient between daily All India Monsoon Rainfall and daily energetics ((a) momentum transport and (b) kinetic energy) of wave 1 at $850 \mathrm{hPa}$.

Figure 1 shows inter-annual and latitudinal variation of correlation coefficient between energetics of wave 1 at $850 \mathrm{hPa}$ and DAIMR. The upper (lower) panel represents the results of momentum transport (kinetic energy) of wave 1 . The shaded areas represent the significant correlations at $99 \%$ and more. The figure clearly indicates that the correlation coefficients are significant between $5^{\circ} \mathrm{N}$ and $15^{\circ} \mathrm{N}$ for all the 54 years. Figure 2 presents the similar result for wave 2 . The significant correlation in case of waves greater than 2 and waves at 500 and $200 \mathrm{hPa}$ are neither stable nor consistent with respect to wave number and latitudinal belt and hence are not presented and discussed.

It is further observed that the effective energetics of waves 1 and 2 is more significantly correlated than that of the individual waves. Figure 3 is similar to figures 1 and 2 except it is for the effective energetics of waves 1 and 2. The maximum correlation for momentum transport is around $10^{\circ} \mathrm{N}$ and for kinetic energy, it is around $15^{\circ} \mathrm{N}$.

We would like to mention that the gridded rainfall data is available only up to 2004 . We have verified the results for 2005-2007. These three years also exhibit similar pattern at $850 \mathrm{hPa}$ but they are not included in the present study because 
(a)

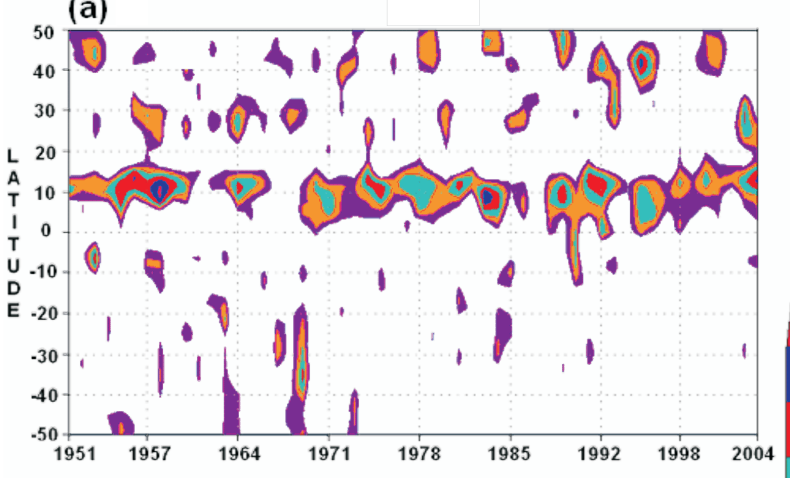

(b)

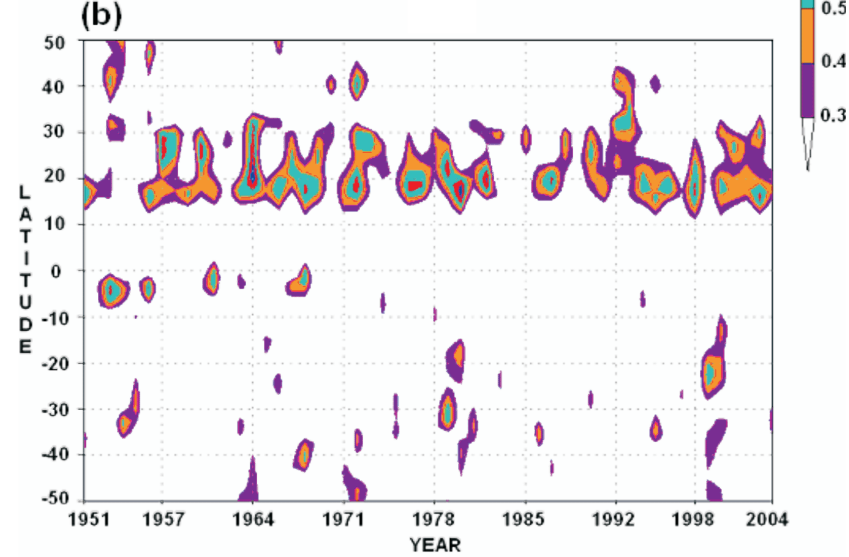

Figure 2. Latitudinal and inter-annual variation of correlation coefficient between daily All India Monsoon Rainfall and daily energetics ((a) momentum transport and (b) kinetic energy) of wave 2 at $850 \mathrm{hPa}$.

their correlation analysis is based on the different rainfall dataset.

Figure 4 gives inter-annual variation of the percentage variance explained by waves 1 and 2 ( $u$-field) around $10^{\circ} \mathrm{N}$. It can be seen that whenever the contribution of wave 1 decreases (increases) the contribution of wave 2 increases (decreases) so that the total variance due to both the waves remains around $85 \%$. Krishnamurty and Kanamitsu (1981) also found $70 \%$ of variance explained by ultra-long waves of the upper troposphere.

Comparison of the climatology (based on 54 years data) of DAIMR and effective energetics of waves 1 and 2 is presented in figure 5 . Days (1 June to 30 September) are along the $\mathrm{X}$-axis and normalised anomalies are along the Y-axis. Correlation between the two series is 0.9. Interesting aspect of this figure is that the response period of rainfall to the energetics is of 5-10 (4-7) days during the onset (withdrawal) phase of monsoon over India and during established phase both the series move hand-in-hand. Here, onset phase means the period taken by the monsoon to cover the Indian landmass. Climatologically the onset period is from 1 June to 15 July and the withdrawal (a)

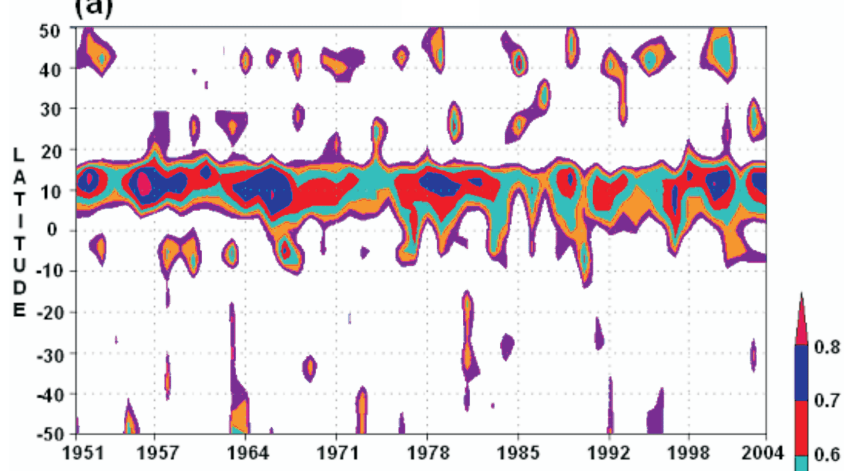

(b)

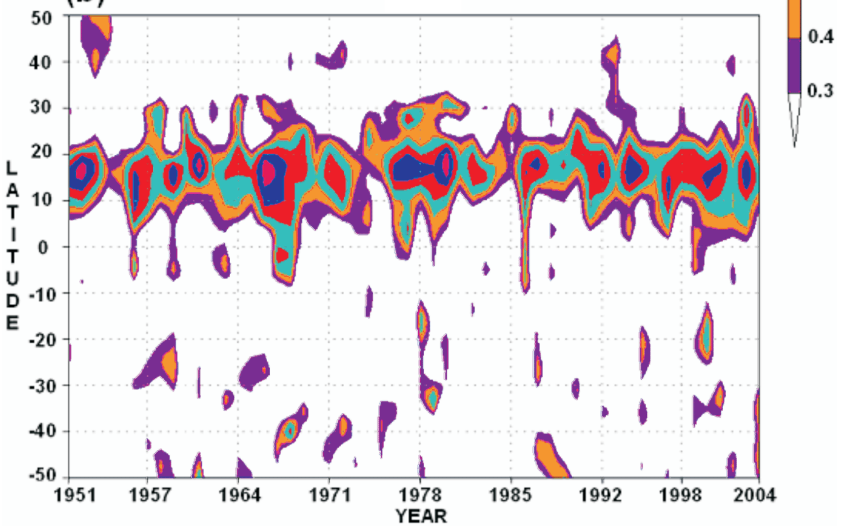

Figure 3. Latitudinal and inter-annual variation of correlation coefficient between daily All India Monsoon Rainfall and daily energetics ((a) momentum transport and (b) kinetic energy) of wave $1+2$ at $850 \mathrm{hPa}$.

phase starts from 1 September. Normalised plots of the energetics of ultra-long waves and rainfall for individual year do not show marked deviation with respect to climatology. Thus, the energetics of ultra-long waves has predictive potential of DAIMR and intra-seasonal behaviour of monsoon can be anticipated particularly during the onset and withdrawal phases of monsoon.

The study clearly brings out that the ultra-long waves not only dominate the lower tropospheric wind field around $10^{\circ} \mathrm{N}$ but also influence the rainfall activity over Indian landmass.

\section{Discussion}

The correlations of daily time series are quite high. Lag-1 auto correlations for all the series are highly significant indicating the existence of persistence within the series. Persistency is the basic property of daily rainfall. A method suggested by Quenouille (1952) is useful here to test the statistical significance of the series having the serial (persistence) correlation through adjusted number of degrees of freedom. The result of the adjusted number of degrees of freedom between daily rainfall and kinetic energy of waves $(1+2)$ around 


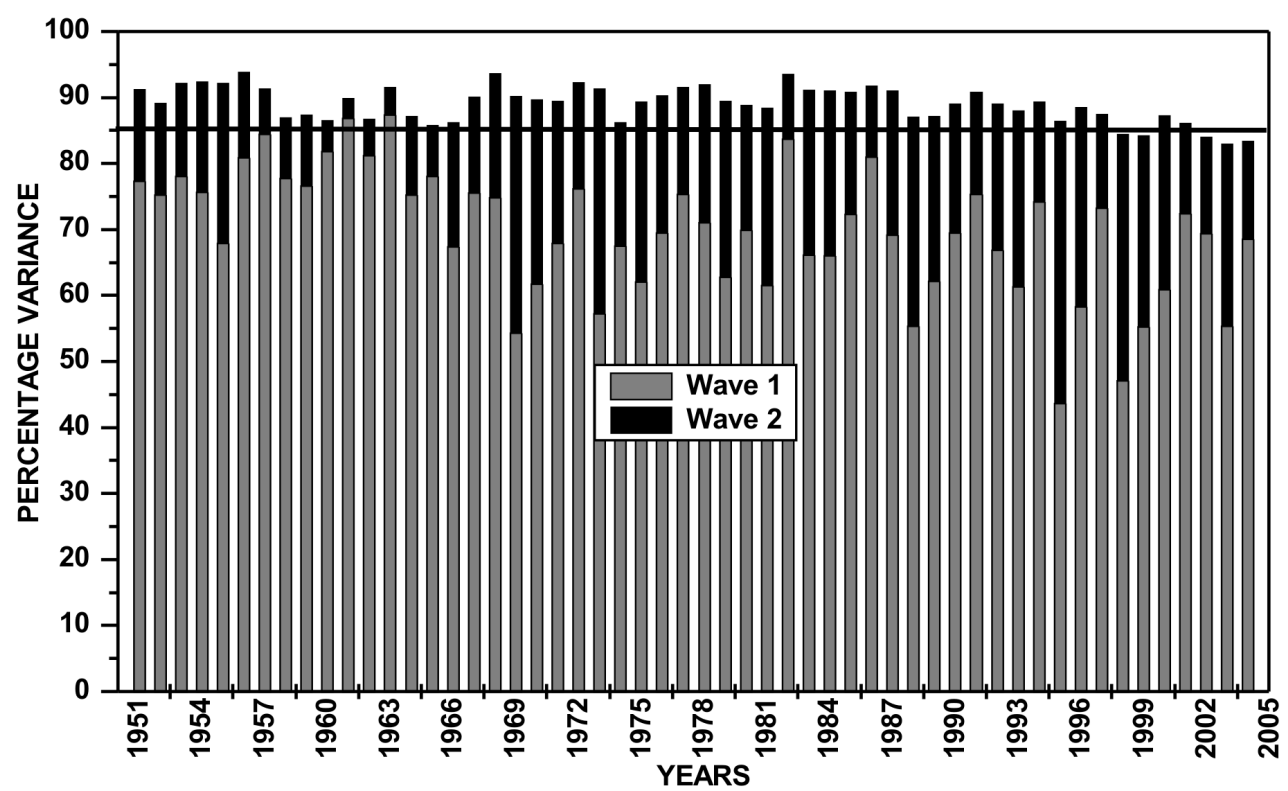

Figure 4. Inter-annual variation of the percentage variance explained by waves 1 and 2 of $u$-field at $850 \mathrm{hPa}$ around $10^{\circ} \mathrm{N}$.
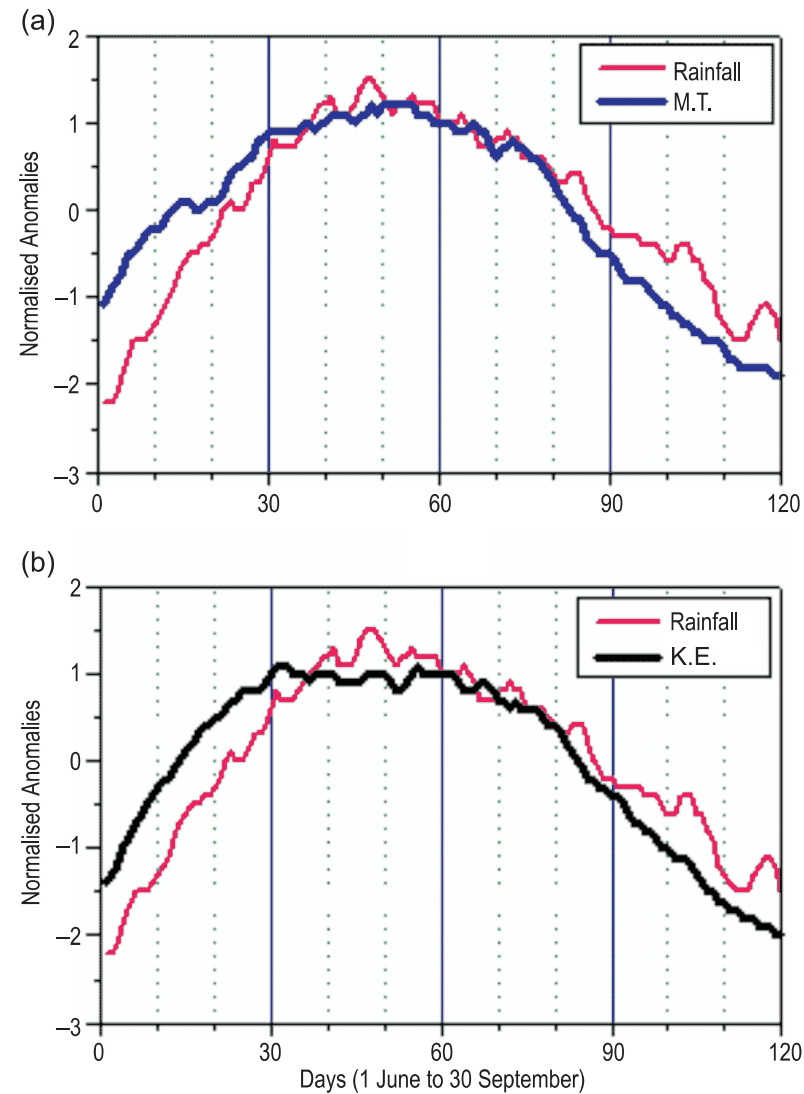

Figure 5. Comparison of climatology of daily All India Monsoon Rainfall with climatology of daily energetics ((a) momentum transport and (b) kinetic energy) of waves $1+2$ at $850 \mathrm{hPa}$ around $10^{\circ} \mathrm{N}$.

$10^{\circ} \mathrm{N}$ is given in figure 6 . The upper panel gives the effective degrees of freedom (actual degrees of freedom is 122). The lower panel gives correlation
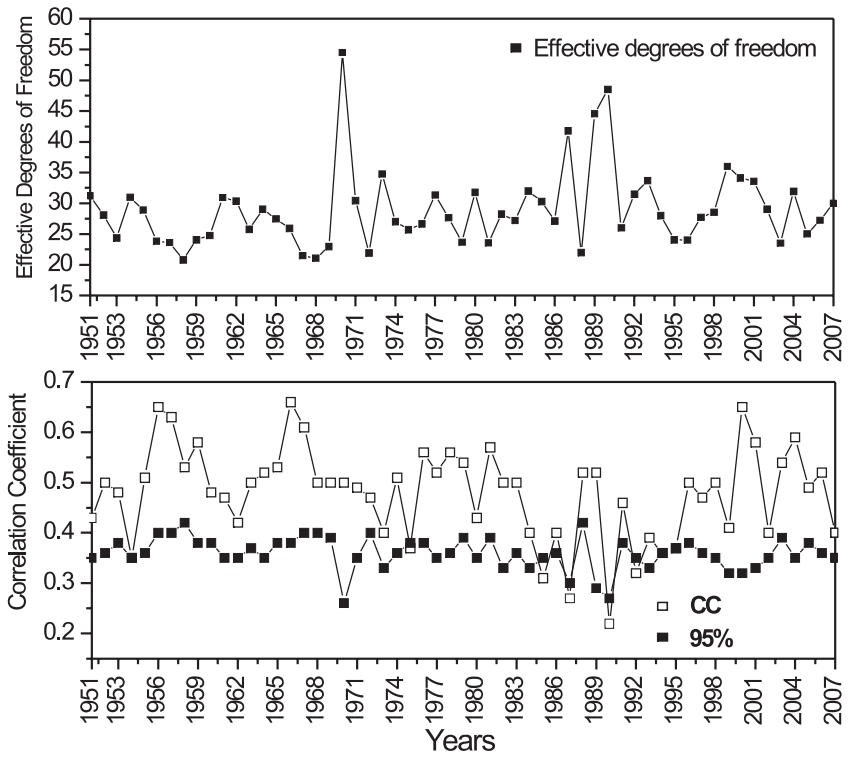

Figure 6. Test of significant levels through effective degrees of freedom.

coefficient (hollow square) and 95\% significant level (solid square) as per the effective degrees of freedom of each year. The effective degrees of freedom vary form year to year and so the significant level changes accordingly. CCs are above the significant level for most of the years indicating that persistency is not the only cause of strong relationship between DAIMR and the energetics of waves 1 and 2 .

Now we would like to address two points, viz.,

(i) what causes the generation of waves 1 and 2 and their dominance around $10^{\circ} \mathrm{N}$ ? and 


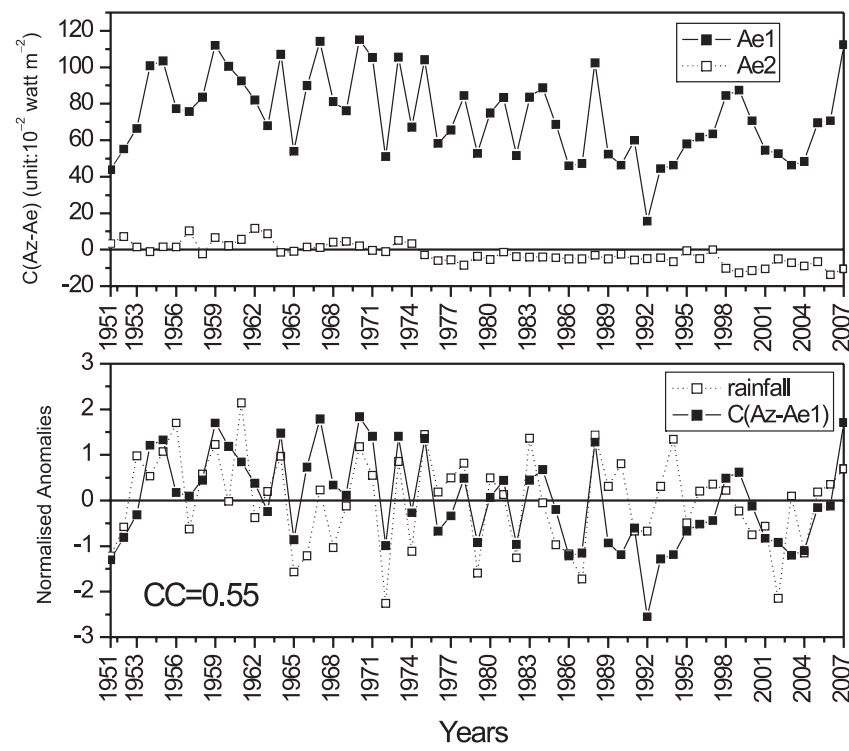

Figure 7. Conversion rates of zonal available potential energy to eddy available potential energy of waves 1 and 2 during monsoon season at $850 \mathrm{hPa}$.

(ii) why should the energetics of ultra-long waves influence the rainfall activity over Indian landmass?

Krishnamurty and Kanamitsu (1981) have pointed out that the physical cause of the generation of waves 1 and 2 is the differential heating due to zonal asymmetry between

- landmasses of Asia and Africa and

- oceans (Atlantic and Pacific) between equator and $30^{\circ} \mathrm{N}$.

This can be further supplemented through the conversion of Zonal Available Potential Energy (Az) to Eddy Available Potential Energy (Ae). The upper panel of figure 7 gives the conversion rates of seasonal (June to September) Az to Ae for waves 1 and 2 at $850 \mathrm{hPa}$ for all the years. Positive values indicate that the conversion is from $\mathrm{Az}$ to Ae. Major part of $\mathrm{Az}$ is being converted into Ae of wave 1 . The lower panel gives the correlation coefficient between seasonal Ae and seasonal AIMR. The correlation is 0.55 which is significant at $99 \%$ level. Thus, APE due to zonal heating during summer monsoon is mainly converted into Ae of wave 1 which in turn show a strong relationship with seasonal rainfall over India.

At this juncture, it would be appropriate to look into the features of wave 1 , wave 2 and wave $1+2$. Figure 8 gives the longitudinal variation of seasonal (June-September) climatology of $u$ at $10^{\circ} \mathrm{N}$ along with its decomposed wave 1 , wave 2 and resultant of waves 1 and 2 . The maximum energy generated by wave 1 and wave 2 is over the Arabian Sea, near the west coast of India. The longitudinal variation

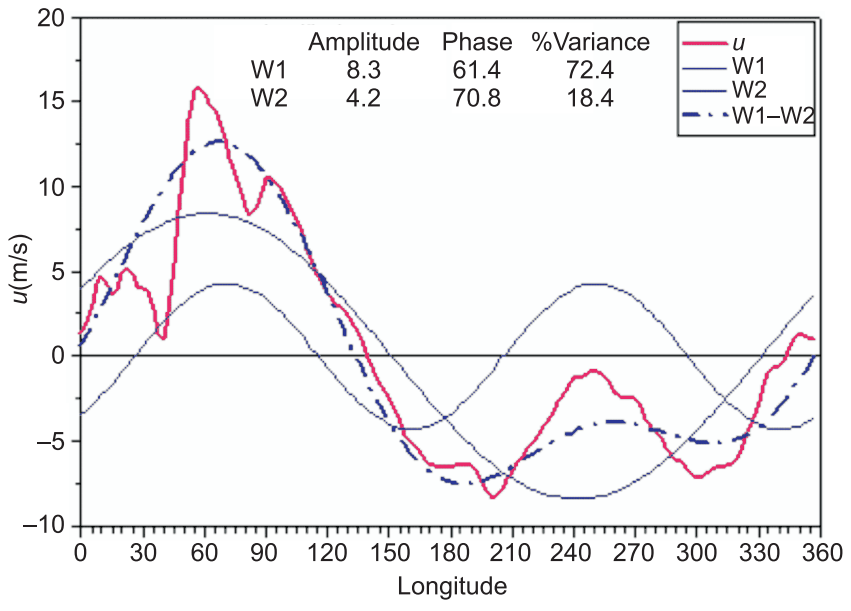

Figure 8. Longitudinal variation of seasonal (June to September) climatology (1951-2004) of $u$-wind at $10^{\circ} \mathrm{N}$ $(850 \mathrm{hPa})$ and the corresponding wave 1 , wave 2 and resultant of waves 1 and 2 .

of the resultant of waves 1 and 2 is almost identical to the variation of the observed $u$ and explains nearly $90 \%$ of the total variance.

During northern summer, centre of the intense convective zone is located in the Bay of Bengal. This zone is responsible for the generation of westerlies to its west and easterlies to its east (lower limb of Walker circulation). East-west circulation is another factor responsible for the generation of wave 1 . This can be further supplemented from the wind field. Figure 9 gives seasonal climatology of vector wind field at $850 \mathrm{hPa}$. The vector wind field is superimposed with the scalar analysis of $u$ component of wind field where positive $u$ (westerlies) is shaded. It can be seen from the figure that the global belt around $10^{\circ} \mathrm{N}$ is covered by westerlies (positive) from $20^{\circ} \mathrm{W}$ to $150^{\circ} \mathrm{E}$ and remaining belt is covered by easterlies (negative). This east-west (negative-positive) combination of wind is responsible for the formation and dominance of wave 1 . Two anticyclonic circulations, one over mid-Pacific and the other over mid-Atlantic Ocean, are mainly responsible for the second larger contribution by the wave 2 .

Low Level Westerly Jet (LLWJ) over the west coast, and the disturbances coming from east and striking the east coast of Indian peninsula are the two major rain producing components of Indian monsoon. The positive portion of resultant of waves 1 and 2 (figure 8) represents the LLWJ and negative portion represents the effect of easterly flow. The energetics of ultra-long waves around $10^{\circ} \mathrm{N}$ is nothing but the quantitative measures of the major rain producing components of Indian monsoon and therefore shows a significant direct relationship with daily rainfall over Indian landmass during monsoon season. 


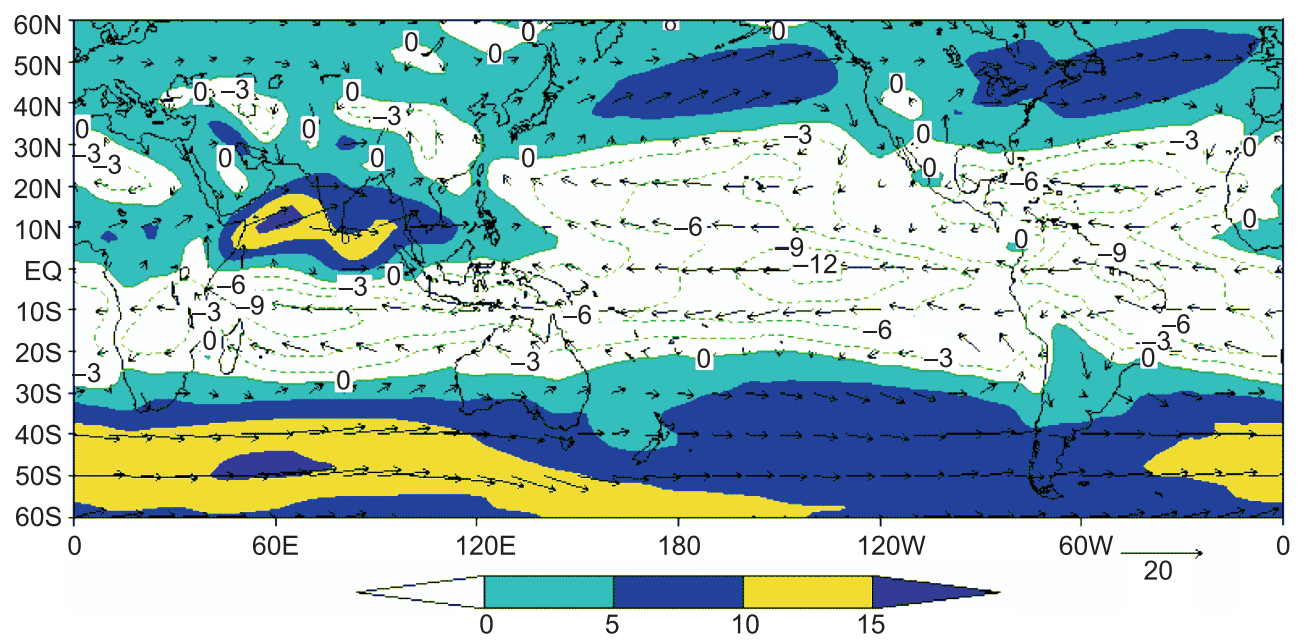

Figure 9. Climatology of seasonal (June to September) wind field at $850 \mathrm{hPa}$.

\section{Conclusions}

The study clearly brings out that the ultra-long waves (waves 1 and 2) not only dominate the lower tropospheric wind field around $10^{\circ} \mathrm{N}$ but also influence the rainfall activity over Indian landmass. The lower tropospheric zonal wind structure is mainly responsible for the dominance of ultra-long waves (waves 1 and 2) around $10^{\circ} \mathrm{N}$ during northern summer. Conversion of $\mathrm{Az}$ to Ae indicates that major portion of $\mathrm{Az}$ is converted into Ae of wave 1 . The response time of the rain to the energetics of the ultra-long waves could be a supporting tool to the short range forecast of rainfall during onset and withdrawal phases of monsoon.

\section{Acknowledgements}

The authors are grateful to Prof. B N Goswami, Director, Indian Institute of Tropical Meteorology, Pune for his encouragement. The authors are also thankful to Dr. P N Mahajan, Head, Forecasting Research Division, for his useful suggestions.

\section{References}

Awade S T, Totagi M Y and Bawiskar S M 1982 Wave to wave and wave to zonal mean flow kinetic energy exchanges during contrasting monsoon years; PAGEOPH $120463-482$.

Asnani G C and Awade S T 1978 Monitoring of semipermanent troughs and ridges in relation to monsoon; Indian J. Met. Hydrol. Geophys. 29(1\&2) 163-169.

Bawiskar S M, Awade S T and Singh S S 1989 Harmonic analysis of summer mean wind at 200 mbar level during contrasting monsoon years over India; Proc. Indian Acad. Sci. (J. Earth Syst. Sci.) 98(4) 365-373.
Bawiskar S M, Chipade M D, Paul D K and Singh S S 1995 Upper and lower tropospheric energetics of standing and transient eddies in wave number domain during summer monsoon of 1991; Proc. Indian Acad. Sci. (J. Earth Syst. Sci.) 104 613-634.

Bawiskar S M 2003 Energetics of zonal waves and performance of Indian summer monsoon rainfall; Ph.D. Thesis, 201.

Bawiskar S M, Chipade M D and Singh S S 2002 Energetics of zonal waves during different phases of monsoon; Mausam 53(1) 1-8.

Bawiskar S M, Chipade M D, Mujumdar V R and Bhide U V 2005a Contrasting features of wave number one during northern summer monsoon seasons of 1997 and 2002; Mausam 56(2) 337-342.

Bawiskar S M, Chipade M D, Mujumdar V R, Puranik P V and Bhide U V 2005b Kinetic energy of extra-tropical waves and their effect on the Indian monsoon rainfall; Mausam 56(3) 681-685.

Keshavamurthy R N and Awade S T 1974 Dynamical abnormalities associated with drought in Asiatic summer monsoon; Indian J. Meteorol. Geophys. 25 257-266.

Krishnamurti T N and Kanamitsu M 1981 Northern summer planetary scale monsoon during drought and normal rainfall months; Monsoon dynamics (eds) Sir James Lighthill and Pearce R P (Cambridge: University Press) 19-48.

Murakami T 1981 Summer mean energetics for standing and transient eddies in wave number domain; In: Monsoon dynamics (eds) Sir James Lighthill and Pearce R P (Cambridge: University Press) pp. 65-80.

Quenouille M H 1952 Assoicated measurement (London: Butterworths) 242.

Rajeevan M, Bhate Jyoti, Kale J D and Lal B 2006 High resolution daily gridded rainfall data for the Indian region: Analysis of break and active monsoon spells. Curr. Sci. 91(3) 295-306.

Raja Rao K S, Awade S T and Harindranathan Nair M V 1983 Monsoon activity and coupling between low latitude and high latitude stratospheric activities; PAGEOPH 121(516) 1035-1048.

Saltzman B 1957 Equations governing the energetics of the larger scaled in the atmosphere turbulence in domain of wave number; J. Meteor. 14 513-523. 
Saltzman B and Fleisher A 1960 The exchange of kinetic energy between large scales of atmospheric motion; Telllus XII $374-377$.
Saltzman B 1970 Large scale atmospheric energetics in the wave number domain; Rev. Geophys. Space Phys. 8 289-302.

MS received 25 September 2008; revised 23 December 2008; accepted 13 January 2009 